\title{
Impact of Thymoquinone on Memory Deficit-associated with Global Cerebral Ischemia-Reperfusion Injury in Rats; Possible Role of PPAR- $\gamma$
}

\author{
Noha I. Hussien ${ }^{*}$, Moataz A. Elawady², Mohammed M. Elmaghrabi², Marwa H. Muhammad ${ }^{1}$ \\ ${ }^{1}$ Department of Physiology, Faculty of Medicine, Benha University, Qalubyia, Egypt drnohaibrahim79@gmail.com \\ ${ }^{1}$ Department of Physiology, Faculty of Medicine, Benha University, Qalubyia, Egypt drmarwahassan448@gmail.com \\ ${ }^{2}$ Department of Neurosurgery, Faculty of Medicine, Benha University, Qalubyia, Egypt moataz_elawady@yahoo.com \\ ${ }^{2}$ Department of Neurosurgery, Faculty of Medicine, Benha University, Qalubyia, Egypt dr elmaghrabi@yahoo.com \\ "Corresponding Author \\ Noha Ibrahim Hussien \\ Physiology Department \\ Benha Faculty of Medicine, \\ Benha University, Qalubyia \\ Egypt \\ E-mail: drnohaibrahim79@gmail.com, noha.ibrahim@,fmed.bu.edu.eg
}

Received:28 July 2019; | Revised:22 August 2019; | Accepted:15 March 2020

\section{Abstract}

Context: Cerebrovascular insults contribute significantly to morbidity and mortality statistics worldwide. More than half of the ischemic stroke survivors experience residual memory deficits. Thymoquinone (TQ) effect on the hippocampus has gained more attention.

Objective: To clarify the impact of TQ administration on memory status-associated with global cerebral ischemia/reperfusion (I/R)-injury in rats and to illustrate the potential role of peroxisome proliferator-activated receptor gamma (PPAR- $\gamma$ ) as a novel suggested mechanism.

Method: Sham, Sham + TQ, I/R, I/R+ TQ, and I/R+ BADGE (selective PPAR- $\gamma$ antagonist) + TQ groups were assigned. Memory status was assessed by the novel object recognition test. Hippocampal content of superoxide dismutase (SOD), glutathione peroxidase (GSH-Px), malondialdehyde (MDA), tumour necrosis factor-alpha (TNF- $\alpha$ ) and interleukin-6 (IL-6), in addition to the expression levels of PPAR- $\gamma$, brain-derived neurotrophic factor (BDNF), and nuclear factor- $\kappa$ B (NF- $\kappa$ B) were evaluated.

Results: Global cerebral I/R impaired the memory functions and increased hippocampal levels of oxidative stress and inflammatory biomarkers. TQ administration to ischemic rats significantly improved the previous parameters with uprising PPAR-y and BDNF but, lowering NF- $\kappa$ B levels. The prior treatment with PPAR- $\gamma$ antagonist significantly attenuated the TQ effect.

Conclusion: TQ exerted nootropic effect against ischemic stroke associated-memory deficits through antioxidant, anti-inflammatory, and neurotrophic mechanisms with PPAR- $\gamma$ contributes, partly at least, toward TQ-mediated protection.

Keywords:Thymoquinone, Memory deficits, PPAR-y, Cerebral ischemia/reperfusion, Novel object recognition test 
List of abbreviations: BADGE; bisphenol A diglycidyl ether, BDNF; brain-derived neurotrophic factor, GSH-Px, glutathione peroxidase, I/R; ischemia/reperfusion, IL-6; interleukine-6, MDA; malondialdehyde, NF- $\mathrm{k}$ B; nuclear factor- $\mathrm{K}$ B, NOR; novel object recognition test, PPAR- $\mathrm{\gamma}$; peroxisome proliferatoractivated receptor gamma, SOD; superoxide dismutase, TNF- a, tumour necrosis factor-alpha, TQ; thymoquinone.

\section{Introduction}

Cerebrovascular disorders have become a major cause of disability and death all over the world ${ }^{[1]}$. More than half of the ischemic stroke survivors experience residual cognitive impairment such as learning disability and memory loss ${ }^{[2]}$. Global cerebral ischemia, the most common clinical feature of circulatory arrest, is a recognized cause for neuronal injury ${ }^{[3]}$. The hippocampus is a vulnerable brain area that firstly suffers damage from ischemic changes. It plays important roles in the consolidation of information from short-term memory to long-term memory, and in spatial memory ${ }^{[4]}$. Numerous processes are tangled in the pathogenesis of ischemic neuronal damage, comprising basically, oxidative stress, inflammation in addition to energy-metabolism disturbance and excitotoxicity ${ }^{[5]}$ that eventually, unsettle synaptic plasticity and long-term potentiation essentials for memory storage mechanisms ${ }^{[6]}$.

The Peroxisome proliferator-activated receptor gamma (PPAR- $\gamma$ ) plays a vital role in regulating multiple biological processes in the brain. This nuclear receptor functions as a principal " gatekeeper" for modulation of transcription factors and a broad range of target genes as a brainderived neurotrophic factor (BDNF), nuclear factor kappa-B (NF- $\kappa$ B), pro-inflammatory cytokines and chemokines, antioxidant enzymes, and among others ${ }^{[7]}$. BDNF plays a fundamental role in neuronal survival and growth, works as a neurotransmitter modulator, and contributes to neuronal plasticity, that is vital for learning and memory functions. It has been identified in most brain areas including the hippocampus and commonly downregulated in rodent models of cerebral neurodegenerative diseases ${ }^{[8]}$. So, uprising BDNF levels could causally improve cerebral I/R injury and its outcomes. Moreover, the proinflammatory transcription factor NF- $\kappa$ B and its downstream inflammatory response pathway have been implicated in the pathogenesis of cerebral stroke ${ }^{[9]}$. Accordingly, PPAR- $\gamma$ is becoming an encouraging therapeutic target in ischemic strokes.

Thymoquinone (TQ), an emerging natural medication with a varied range of medical applications, is the primary active ingredient in the seeds of Nigella sativa, known as black cumin in English and "Habbat Al-Barakah" in Arabic ${ }^{[10]}$. It was described as a potent neuroprotective agent against neural injury-induced by forebrain ischemia [11]. It also exerted a potential anticonvulsant activity against petit-mal epilepsy ${ }^{[12]}$. Moreover, a recently published study has highlighted a potential therapeutic cross-talk between TQ and PPAR- $\gamma$ in spinal cord injury ${ }^{[13]}$. We, therefore, assumed that TQ might maintain the hippocampus integrity following cerebral I/R injury via PPAR- $\gamma$-dependent pathway.

In spite of the accumulating data about the TQ protective property against memory impairments in diabetes [14], hypothyroidism [15], and following lipopolysaccharides and amyloid- $\beta$ injection ${ }^{[16,17]}$, TQ impact on global cerebral $\mathrm{I} / \mathrm{R}$ - induced memory impairment remains to established. In view of these considerations, this study was designed to evaluate the possible neuroprotective impact of TQ on memory deficits associated with global cerebral $\mathrm{I} / \mathrm{R}$ using the novel object recognition test (NOR) to assess memory function and to outline the possible involvement of PPAR- $\gamma$ pathway and its modulation by bisphenol-A-diglycidyl ether (BADGE), a selective PPAR- $\gamma$ antagonist ${ }^{[18]}$, as a novel mechanism in such effect within the hippocampus.

\section{Materials and Methods}

\subsection{Animals}

Adult male Wistar rats weighing 220-240 g were obtained from the Experimental Animal Unit of the Faculty of Veterinary Medicine. Animals were given standard laboratory diet and water ad 
libitum. Animal handling and experimental procedures were performed according to the National Institute of Health Guide for the Care and Use of Laboratory Animals. The experimental protocol was approved by the Animal Research Ethics Committee at Faculty of Medicine, Benha University (REC-FOMBU, MoHP No:0018122017/ Certificate No.: 1017, June-2018), Egypt.

\subsection{Experimental design and TQ administration}

In this study, forty rats were randomly assigned to five groups $(n=8)$ each: sham-operated group; cerebral I/R group; sham-TQ treated group, cerebral I/R-TQ treated group, and cerebral I/RBADGE-TQ treated group. The TQ-treated groups received TQ (Sigma-Aldrich Co., USA.) at (10 $\mathrm{mg} / \mathrm{kg}$, i.p.) dissolved in ethanol and diluted with saline immediately after surgery then, once daily for 14 days ${ }^{[16]}$. In cerebral I/R-BADGE-TQ treated group, the PPAR- $\gamma$ selective inhibitor, Bisphenol A diglycidyl ether (BADGE) (Sigma-Aldrich Co., USA.) was dissolved in ethanol, diluted with saline, and given at a dose of (30 mg/kg i.p.) ${ }^{[19]}, 30 \mathrm{~min}$ before TQ administration. The rats from the sham and cerebral I/R untreated groups received an equal volume of the solvent at the same time.

\subsection{Induction of global cerebral ischemia/reperfusion (I/R)}

The rats were subjected to global cerebral I/R or sham surgery under urethane anesthesia $(1 \mathrm{~g} / \mathrm{kg}$; i.p.). A median neck incision was performed. The muscles' planes and trachea deviated and common carotid arteries were freed from the surroundings. Rats were subjected to bilateral common carotid artery occlusions using blunt mini clamps for 30 min. followed by slow declamping. Sham-operated rats were treated identically without occluding carotid arteries. Skin to skin stitch and intraperitoneal antibiotic injection were given ${ }^{[20]}$.

\subsection{Memory assessment by novel object recognition test}

Novel object recognition test (NOR) is a frequently used behavioral assay for the study of learning and memory in rodents. It is based on an innate preference of rats for novelty ${ }^{[21]}$. In this task, normal rats spend more time exploring a novel object than they spend exploring a familiar object; reflecting their memory of the familiar object. This task does not involve positive or negative reinforcement and has clear parallels with human recognition memory ${ }^{[22]}$.

Briefly, the animals are exposed to two identical objects and memory is evaluated in a second test trial by exchanging one of the familiar objects for a novel one. It has consisted of an open box $\left(100 \times 100 \mathrm{~cm}^{2}\right.$, and $50 \mathrm{~cm}$ high) made of wood, painted gray inside. The objects to be differentiated were available in copies and were made of plastic, glass or metal and the animals could not move them through the arena ${ }^{[22]}$.

The test composed of 3 phases; habituation, familiarization, and proper testing sessions:

-Habituation: One day after the surgery, the rat was allowed to explore the empty box for 5-min each day for 4 days.

-Familiarization or sample phase: $24 \mathrm{hs}$ after the last habituation session, the animal was trained for recognition of two identical objects placed in the test arena in two opposite and equidistant locations for 3-min.

-Proper testing session or choice phase: $2 \mathrm{hs}$, 24hs, and 7days after the familiarization phase, animals were again placed for 3-min in the testing box ${ }^{[21]}$. During each one of these trials, one copy of the familiar objects used during the sample phase was introduced along with a novel object. To avoid confounds by lingering olfactory stimuli and preferences, the objects and the arena were cleaned with $70 \%$ ethanol after each trial ${ }^{[22]}$.

\subsection{Performance measures and analyses}

Exploration of an object was defined as directing the nose to the object at a distance $2 \mathrm{~cm}$ and/or touching it with the nose. Conversely, turning around or sitting on the object was not considered as exploratory behavior.

The basic measure was the time spent by the rat in exploring objects during the sample phase and during the choice phase using a stopwatch. A video camera was positioned over the NOR arena and the behavior were recorded using a video tracking system for offline analyses for the following measures:

e1: The total time spent exploring the two identical objects in the sample phase (novel + familiar) (seconds). 
e2: The total time spent exploring the two objects in the choice phase (novel + familiar) (seconds).

d1: The discrimination index, which is the difference in time spent exploring the two objects in the choice phase, i.e. (time spent for the novel object - time spent for the familiar object) (seconds).

$\mathrm{d} 2$ : The discrimination ratio, which is the difference in exploration time between the novel and familiar objects (d1) divided by the total time spent exploring the two objects in the choice phase (e2) i.e. (novel - familiar / novel + familiar). This ratio makes it possible to adjust for any differences in the total amount of exploration time ${ }^{[22]}$.

The general experimental design and memory assessment protocol are shown in Figure 1 and Figure 2, respectively.

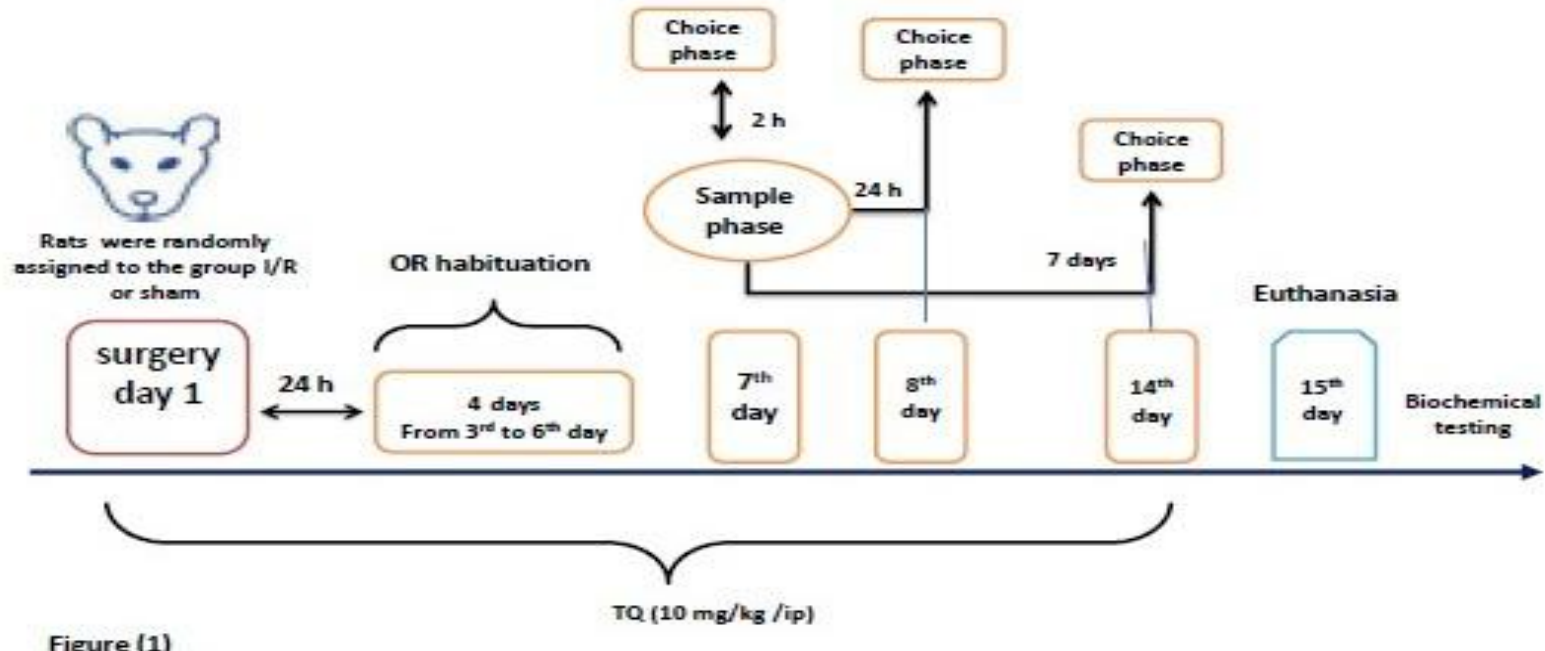

Figure 1: Schematic diagram giving an overall picture of the sequential order of the memory tasks and TQ injection in the experimental groups. TQ; Thymoquinone, OR; object recognition test

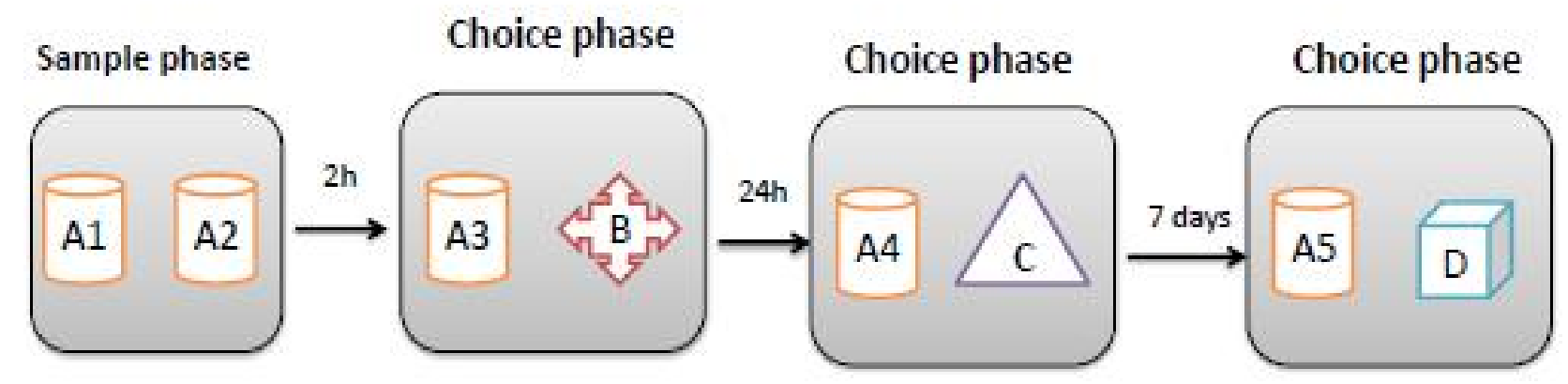

Figure (2)

Figure 2: Drawing illustrating the sample phase and the choice phases of the novel object recognition memory test.A1, A2, A3, A4, and A5 indicate copies of the familiar object. B, C, and D indicate different novel objects

\subsection{Sacrifice and tissue preparation}

Rats were decapitated $24 \mathrm{~h}$ after the last behavioral experiments. Brains were quickly removed and hippocampi were isolated on a cold stage and frozen in liquid nitrogen then stored at $80{ }^{\circ} \mathrm{C}$ till analysis. One part was homogenized 
(Teflon-glass homogenizer) in $0.25 \mathrm{M}$ sucrose buffer. The homogenate was then, centrifuged at $9000 \mathrm{rpm}$ for $15 \mathrm{~min}$ at $4{ }^{\circ} \mathrm{C}$, and the supernatants were collected for biochemical analysis. The other one was stored in RNA stabilizing reagent (Qiagen Inc., Valencia, CA) at $10 \mu \mathrm{L}$ per $1 \mathrm{mg}$ of tissue then stored at $-80{ }^{\circ} \mathrm{C}$ for RNA extraction.

\subsection{Biochemical analysis of hippocampal oxidative stress and inflammatory markers}

The colorimetric superoxide dismutase (SOD) activity assay kits (No. 706002, Cayman Chemical Co., MI, USA) were used according to the method described by Sun et al. ${ }^{[23]}$.

The colorimetric glutathione peroxidase (GSHPx) activity assay kits (No. 703102, Cayman Chemical Co., MI, USA), were used to determine the GSH-Px activity spectrophotometrically [24].

The level of malondialdehyde (MDA), a marker for the degree of lipid peroxidation in the hippocampal neuronal tissue, was determined by measuring a thiobarbituric acid reactive substance in the tissue homogenate ${ }^{[25]}$.

The hippocampal levels of the inflammatory cytokines (TNF- a ) and interleukins-6 (IL-6) were assessed by using specific rat ELISA kits (ab100785 and ab100772 kits respectively, Abcam, Cambridge, UK), by following the manufacturer' $\mathrm{s}$ instructions.

\subsection{Real-time quantitative PCR (RT-qPCR) testing for PPAR- $\gamma, \mathrm{BDNF}$, and NF- $\kappa$ B}

Total RNA was isolated from $25 \mathrm{mg}$ hippocampal tissue using total RNA purification kit (Jena Bioscience Germany). It was further analyzed for quantity and quality with a dual beam spectrophotometer (Beckman Coulter, Fullerton, California, USA). For quantitative expression of PPAR- $\gamma$, BDNF, and NF- $\kappa$ B genes, the following procedure was performed; $200 \mathrm{ng}$ of the total RNA from each sample was used for cDNA synthesis by reverse transcription using High Capacity cDNA Reverse Transcriptase kit (Applied Biosystems Inc., Foster City, CA, USA). The cDNA was subsequently amplified with the SYBR Green OneStep PCR Master Kit in a 48-well plate (Applied Biosystems Inc., Foster City, CA, USA) as follows: 10 minutes at $95^{\circ} \mathrm{C}$ for enzyme activation followed by 40 cycles of 15 seconds at $95^{\circ} \mathrm{C}, 20$ seconds at $55^{\circ} \mathrm{C}$, and 30 seconds at $72^{\circ} \mathrm{C}$ for the amplification step. According to the RQ manager program ABI SDS software (ABI 7900), the data are produced as sigmoid shaped amplification plots in which the number of cycle is plotted against fluorescence. Fluorescent emission data were captured and mRNA levels were analysed using the critical threshold (CT) value. Changes in the expression of each target gene were normalized relative to the mean $\mathrm{CT}$ values of GAPDH housekeeping gene by the $2^{-\Delta \Delta C T}$ method [26] $1 \mu \mathrm{L}$ of both primers specific for each target gene were used. Primer sequence specific for each gene were as follow:

- PPAR- $\gamma$ : Forward: 5 ' CCCACCAACTTCGGAATCAG -3'

Reverse: $5^{\prime}$ -

GGAATGGGAGTGGTCATCCA-3'

BDNF: $\quad$ Forward

5

AGTGATGACCATCCTTTTCCTTAC3 ',

CCTCAAATGTGTCATCCAAGGA -3`.

Reverse 5'-

NF- $\quad \kappa \quad B$ : Forward 5'-:

GCTACACAGAGGCCATTGAA3',

Reverse 5'-

ATGTGCTGTCTTGTGGAGGA3`.

GAPDH: Forward: 5

GTGGTGAAGCAGGCATCTG-3'

Reverse:

AGCCGTATTCATTGTCATACCA-3' .

\subsection{Statistical analysis}

All data were analyzed using the program Statistical Package for Social Sciences (SPSS) version 19 (SPSS Inc., Chicago, Illinois, USA). Data are presented as the mean \pm standard deviation (SD). Comparisons of all parameters among the study groups were performed by using one-way analysis of variance (ANOVA) with LSD post-hoc to compensate for multiple comparisons. A $\mathrm{P}$ value $<0.05$ was considered statistically significant. 


\section{Results}

3.1 Effects on object recognition memory in the experimental groups; total time spent exploring objects in the sample phase (e1), discrimination index (d1), and discrimination ratio (d2) (Fig. 3 \& Table 1)

The present study revealed no significant differences between the overall time spent exploring two identical objects presented during the familiarization phase among all experimental groups $(\mathrm{P}>0.05)$ (Fig. 3A). In the choice phases
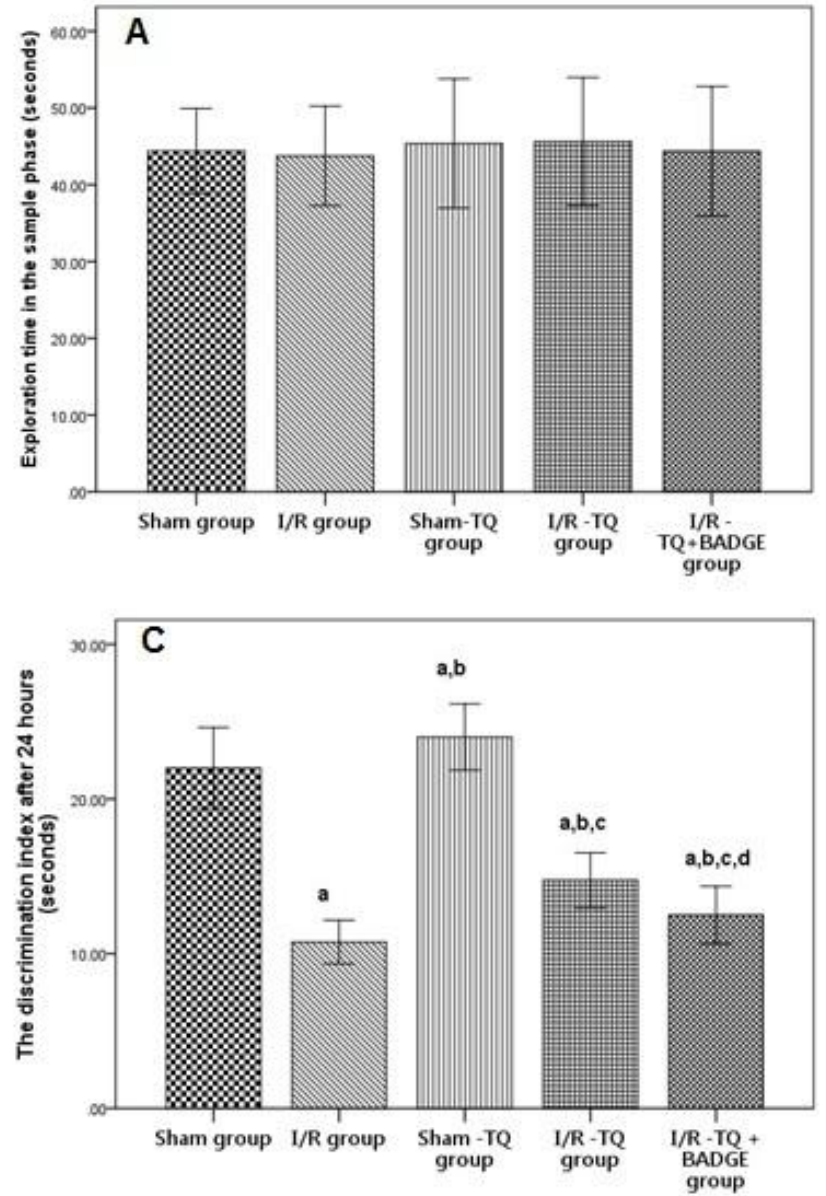

2hs, 24hs and 7days after the familiarization phase, the rats in sham group tend to explore a novel object more than a familiar one. This discrimination was significantly decreased in rats exposed to global cerebral I/R surgery, indicating disturbed memory for the familiar one. The difference between time they spent exploring the novel object and the familiar one, $(\mathrm{d} 1)$, and the discrimination ratio $(\mathrm{d} 2)$ was significantly decreased in ischemic group versus the sham one $(\mathrm{P}<0.05)$.
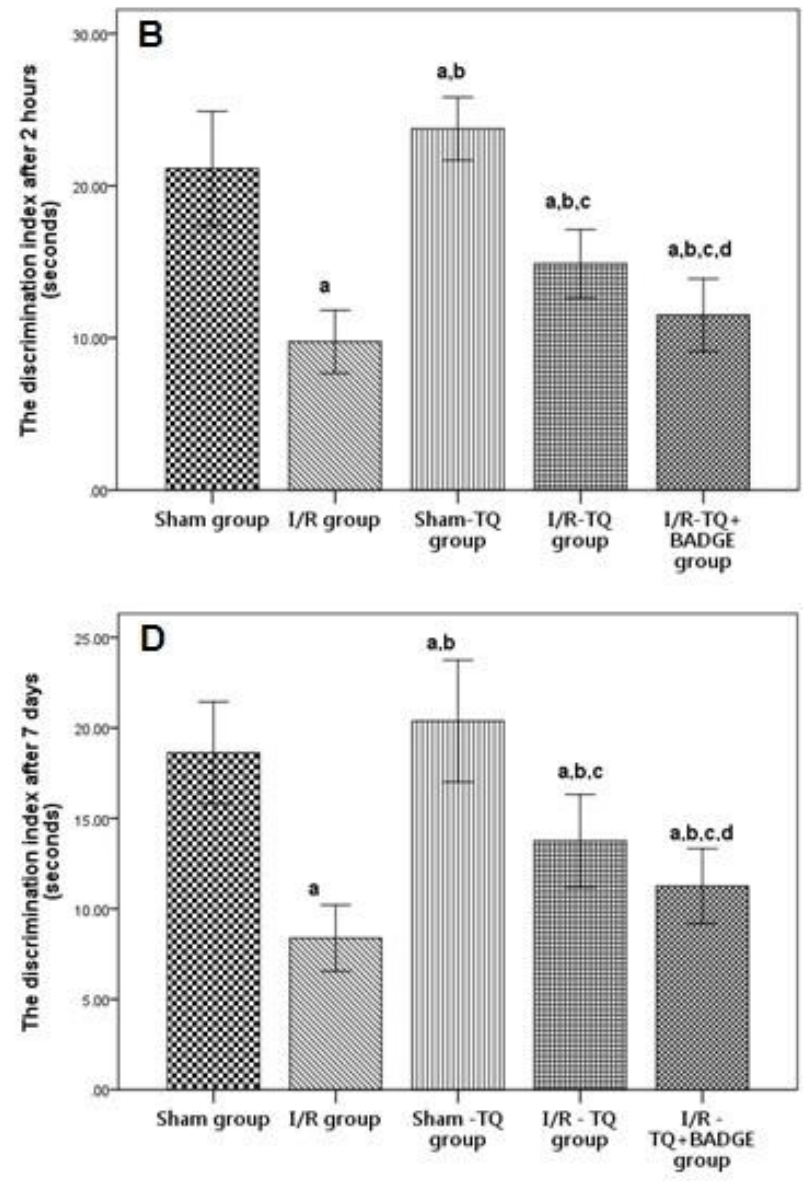

Figure 3: Changes in the $\mathrm{e} 1$ and $\mathrm{d} 1$ of NOR test in the experimental groups

(A) Time spent exploring the objects during the sample phase by rats in the experimental groups; (B), Discrimination index during the choice phase 2 hours after the sample phase in the experimental groups; (C), Discrimination index during the choice phase 24 hours after the sample phase in the experimental groups; (D), Discrimination index during the choice phase 7days after the sample phase in the experimental groups. Data is expressed as mean \pm standard deviation ( $\mathrm{n}=8$ per group). $\mathrm{P}<0.05$ is significantly tested by using One-way analysis of variance (ANOVA) and Post Hoc multiple comparisons (LSD). ${ }^{a} \mathrm{P}<0.05$ vs. sham group; ${ }^{b} \mathrm{P}<0.05$ vs. cerebral I/R group; ${ }^{\mathrm{c}} \mathrm{P}<0.05$ vs. Sham-TQ treated group; ${ }^{\mathrm{d}} \mathrm{P}<0.05$ vs. cerebral I/R-TQ treated group. $\mathrm{I} / \mathrm{R}$; ischemia/reperfusion, TQ; thymoquinone, BADGE; bisphenol A diglycidyl ether 
TQ-treated cerebral $\mathrm{I} / \mathrm{R}$ rats spent more time exploring a novel object compared to the familiar one, causing significant increase in the discrimination index and ratio (d1) and (d2); $2 \mathrm{hs,}$ 24hs, and 7days choice phases when compared with the cerebral $\mathrm{I} / \mathrm{R}$ group $(\mathrm{P}<0.05)$. This indicates recognition memory is intact. On the other hand, BADGE-pretreatment to cerebral I/R-TQ group caused disturbed discrimination for both familiar and novel objects hence; an observed significant (P $<0.05)$ decrease in both (d1) and (d2) - 2hs, 24hs, and 7 days choice phases was documented in BADGE-pretreated when compared with cerebral I/R-TQ group. In addition, a significant $(\mathrm{P}<0.05)$ increase in the (d1) and (d2) was observed in TQtreated sham group compared to the untreated one (Fig. 3 B, C, D \& Table 1).

Table 1: Changes in discrimination ratio (d2) in NOR test in the experimental groups

\begin{tabular}{|l|l|l|l|l|l|}
\hline & $\begin{array}{l}\text { Sham } \\
\text { group }\end{array}$ & $\begin{array}{l}\text { Cerebral I/R } \\
\text { group }\end{array}$ & $\begin{array}{l}\text { Sham-TQ } \\
\text { treated } \\
\text { group }\end{array}$ & $\begin{array}{l}\text { Cerebral I/R - } \\
\text { TQ treated } \\
\text { group. }\end{array}$ & $\begin{array}{l}\text { Cerebral I/R- } \\
\text { BADGE+TQ } \\
\text { treated group. }\end{array}$ \\
\hline $\begin{array}{l}\mathrm{d} 2-2 \text { hours-choice } \\
\text { phase }\end{array}$ & $0.72 \pm 0.02$ & $0.15 \pm 0.02^{\mathrm{a}}$ & $0.82 \pm 0.03^{\mathrm{ab}}$ & $0.42 \pm 0.02^{\mathrm{abc}}$ & $0.23 \pm 0.02^{\mathrm{abcd}}$ \\
\hline $\begin{array}{l}\mathrm{d} 2-24 \text { hours-choice } \\
\text { phase. }\end{array}$ & $0.71 \pm 0.02$ & $0.13 \pm 0.02^{\mathrm{a}}$ & $0.82 \pm 0.03^{\mathrm{ab}}$ & $0.46 \pm 0.03^{\mathrm{abc}}$ & $0.25 \pm 0.02^{\mathrm{abcd}}$ \\
\hline $\begin{array}{l}\mathrm{d} 2-7 \text { days -choice } \\
\text { phase. }\end{array}$ & $0.72 \pm 0.03$ & $0.14 \pm 0.01^{\mathrm{a}}$ & $0.81 \pm 0.02^{\mathrm{ab}}$ & $0.42 \pm 0.02^{\mathrm{abc}}$ & $0.23 \pm 0.02^{\mathrm{abcd}}$ \\
\hline
\end{tabular}

Data is expressed as mean \pm standard deviation ( $\mathrm{n}=8$ per group). $\mathrm{P}<0.05$ is significant tested by using One-way analysis of variance (ANOVA) and Post Hoc multiple comparisons (LSD). ${ }^{\text {a }} \mathrm{P}<0.05$ vs. sham group; ${ }^{\text {b }}<0.05$ vs. cerebral I/R group; ${ }^{\mathrm{c}} \mathrm{P}<0.05$ vs. Sham-TQ treated group; ${ }^{\mathrm{d}} \mathrm{P}<0.05$ vs. cerebral I/R-TQ treated group. I/R; ischemia/reperfusion, TQ; thymoquinone, BADGE; bisphenol A diglycidyl ether

\subsection{Effect of TQ on hippocampal oxidative stress markers in the experimental groups (Table 2)}

Significant SOD and GSH-Px increases and MDA decrease were documented in cerebral $\mathrm{I} / \mathrm{R}$ rats when compared with the sham group $(\mathrm{P}<0.05)$. While TQ treatment to cerebral $\mathrm{I} / \mathrm{R}$ rats significantly increased the SOD and GSH-Px levels while significantly decreased MDA levels compared to the cerebral $\mathrm{I} / \mathrm{R}$ untreated group $(\mathrm{P}<0.05)$. Conversely, BADGE-pretreatment to cerebral I/R-TQ group significantly decreased the SOD and GSH-Px levels but increased the MDA level when compared with the cerebral I/R-TQ treated group. A significant $(\mathrm{P}<0.05)$ increase in the SOD and GSH-Px level and decrease in the MDA level was observed in the TQ-treated sham group when compared with the sham group.

Table 2: Hippocampal oxidative stress markers in the experimental groups

\begin{tabular}{|l|c|l|c|c|c|}
\hline & Sham group & $\begin{array}{l}\text { Cerebral I/R } \\
\text { group }\end{array}$ & $\begin{array}{l}\text { Sham-TQ } \\
\text { treated group }\end{array}$ & $\begin{array}{l}\text { Cerebral I/R -TQ } \\
\text { treated group. }\end{array}$ & $\begin{array}{l}\text { Cerebral I/R } \\
\text { BADGE+TQ } \\
\text { treated group. }\end{array}$ \\
\hline $\begin{array}{l}\text { SOD (U/mg } \\
\text { protein) }\end{array}$ & $34.3 \pm 2.3$ & $14.9 \pm 1.2^{\mathrm{a}}$ & $40.6 \pm 2.1^{\mathrm{ab}}$ & $24.3 \pm 1.7^{\mathrm{abc}}$ & $18.1 \pm 1.2^{\mathrm{abcd}}$ \\
\hline $\begin{array}{l}\text { GSH-px(U/g } \\
\text { protein) }\end{array}$ & $84.8 \pm 4.6$ & $26.3 \pm 4.6^{\mathrm{a}}$ & $91.6 \pm 2.8^{\mathrm{ab}}$ & $58 \pm 3.7^{\mathrm{abc}}$ & $36.3 \pm 2.9^{\mathrm{abcd}}$ \\
\hline $\begin{array}{l}\text { MDA(nmol/mg } \\
\text { protein) }\end{array}$ & $3.3 \pm 0.34$ & $8.5 \pm 0.39^{\mathrm{a}}$ & $2.5 \pm 0.2^{\mathrm{ab}}$ & $4.3 \pm 0.21^{\mathrm{abc}}$ & $6.7 \pm 0.56^{\mathrm{abcd}}$ \\
\hline
\end{tabular}

Data is expressed as mean \pm standard deviation ( $\mathrm{n}=8$ per group). $\mathrm{P}<0.05$ is significant tested by using One-way analysis of variance (ANOVA) and Post Hoc multiple comparisons (LSD). ${ }^{a} \mathrm{P}<0.05$ vs. sham group; ${ }^{\mathrm{b}} \mathrm{P}<0.05$ vs. cerebral I/R group; ${ }^{\mathrm{c}} \mathrm{P}<0.05$ vs. Sham-TQ treated group; ${ }^{\mathrm{d}} \mathrm{P}<0.05$ vs. cerebral I/R-TQ treated group. SOD, Superoxide dismutase; GSH-Px, glutathione peroxidase, MDA; malondialdehyde, I/R; ischemia/reperfusion, TQ; thymoquinone, BADGE; bisphenol A diglycidyl ether 
3.3 Effect of TQ on hippocampal inflammatory response markers in the experimental groups (Table 3)

The levels of inflammatory mediators TNF- $\alpha$ and IL- 6 in the cerebral $\mathrm{I} / \mathrm{R}$ group were significantly higher compared with the sham group $(\mathrm{P}<0.05)$. Importantly, TNF- $\alpha$ and IL- 6 levels were significantly decreased in $\mathrm{I} / \mathrm{R}-\mathrm{TQ}$ group compared with $\mathrm{I} / \mathrm{R}$ group $(\mathrm{P}<0.05)$. While, BADGE-pretreatment caused a significant increase $(\mathrm{P}<0.05)$ in TNF- $\alpha$ and IL- 6 levels versus I/R-TQ group.

Table 3: Hippocampal inflammatory markers in the experimental groups

\begin{tabular}{|r|c|c|c|c|c|}
\hline & $\begin{array}{c}\text { Sham } \\
\text { group }\end{array}$ & $\begin{array}{c}\text { Cerebral I/R } \\
\text { group }\end{array}$ & $\begin{array}{c}\text { Sham-TQ } \\
\text { treated group }\end{array}$ & $\begin{array}{c}\text { Cerebral I/R } \\
- \text { TQ treated } \\
\text { group. }\end{array}$ & $\begin{array}{c}\text { Cerebral I/R - } \\
\text { BADGE+TQ } \\
\text { treated group. }\end{array}$ \\
\hline $\begin{array}{r}\text { TNF- } \alpha \text { (pg/mg } \\
\mathrm{protein})\end{array}$ & $105.4 \pm 6.5$ & $406 \pm 7.9^{\mathrm{a}}$ & $96.6 \pm 5.4^{\mathrm{b}}$ & $193.8 \pm 7.9^{\mathrm{abc}}$ & $324.9 \pm 14.9^{\mathrm{abcd}}$ \\
\hline $\begin{array}{r}\mathrm{IL}-6(\mathrm{pg} / \mathrm{mg} \\
\mathrm{protein})\end{array}$ & $3.4 \pm 0.9$ & $11.3 \pm 1^{\mathrm{a}}$ & $2.6 \pm 0.13^{\mathrm{b}}$ & $6.4 \pm 0.9^{\mathrm{abc}}$ & $9.1 \pm 0.8^{\mathrm{abcd}}$ \\
\hline
\end{tabular}

Data is expressed as mean \pm standard deviation ( $\mathrm{n}=8$ per group). $\mathrm{P}<0.05$ is significant tested by using One-way analysis of variance (ANOVA) and Post Hoc multiple comparisons (LSD). ${ }^{\text {a }} \mathrm{P}<0.05$ vs. sham group; ${ }^{\text {b }}<0.05$ vs. cerebral I/R group; ${ }^{\mathrm{c}} \mathrm{P}<0.05$ vs. Sham-TQ treated group; ${ }^{\mathrm{d}} \mathrm{P}<0.05$ vs. cerebral I/R-TQ treated group. TNF- $\alpha$; tumor necrosis factor-alpha, IL-6; interleukins-6, I/R; ischemia/reperfusion, TQ; thymoquinone, BADGE; bisphenol A

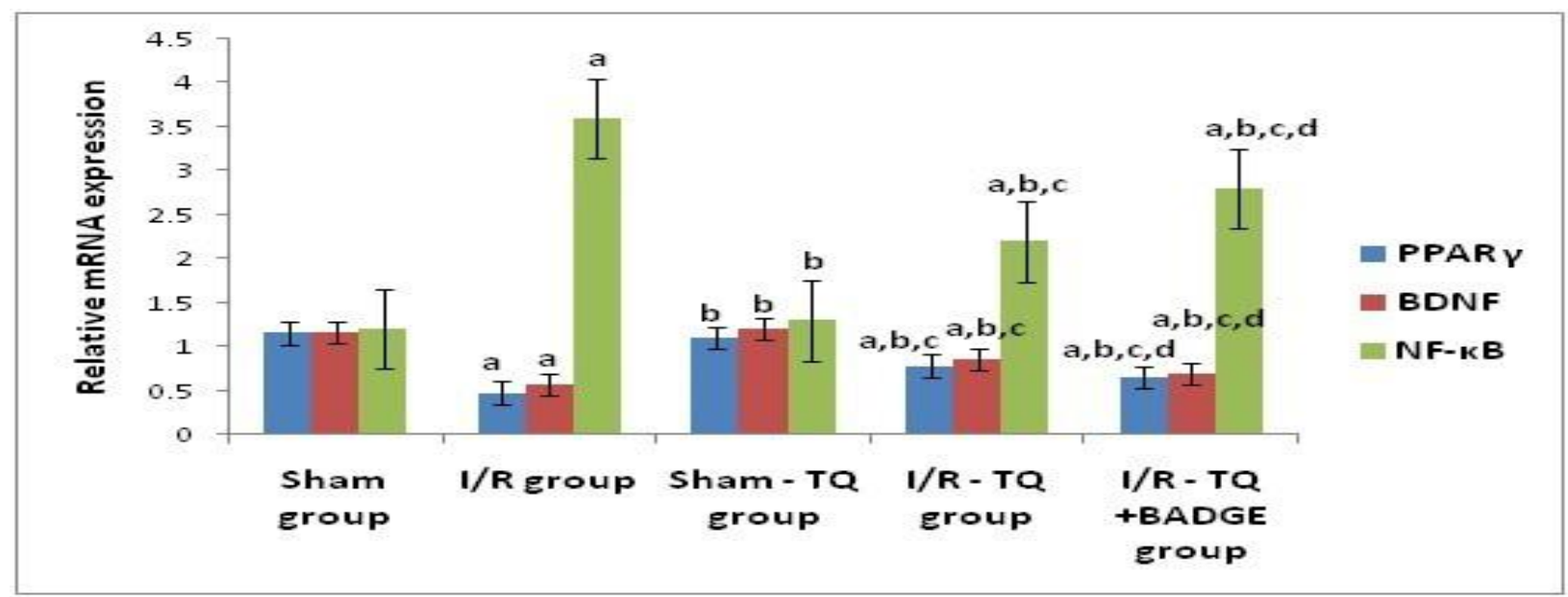

Figure 4: Changes in relative mRNA expression of PPAR- $\gamma$, BDNF, and NF- $\kappa B$ in the hippocampus of the experimental groups. Data is expressed as mean \pm standard deviation $(n=8$ per group). $P<0.05$ is significantly tested by using One-way analysis of variance (ANOVA) and Post Hoc multiple comparisons (LSD). ${ }^{\mathrm{a}} \mathrm{P}<0.05$ vs. sham group; ${ }^{\text {b } P<0.05}$ vs. cerebral I/R group; ${ }^{\mathrm{c}} \mathrm{P}<0.05$ vs. Sham-TQ treated group; ${ }^{\mathrm{d}} \mathrm{P}<0.05$ vs. cerebral I/RTQ treated group. I/R; ischemia/reperfusion, TQ; thymoquinone, BADGE; bisphenol A diglycidyl ether. PPAR\&; peroxisome proliferator-activated receptor-gamma, BDNF; brain-derived neurotrophic factor, NF-кB; nuclear factor- $\mathrm{kB}$

3.4 Effect of TQ on hippocampal PPAR- $\gamma$, BDNF, and NF- $k$ B expressions in the experimental groups (Fig. 4)

To further characterize the mechanism of TQ in cerebral I/R injury, PPAR- $\gamma, \mathrm{BDNF}$, and NF- $\kappa \mathrm{B}$ mRNA expressions were analyzed. PPAR- $\gamma$ and BDNF expressions were significantly decreased while NF- $\mathrm{B}$ expression was significantly increased in the hippocampus of cerebral I/R-untreated rats as compared with the sham group $(\mathrm{P}<0.01)$. TQ administration to cerebral $\mathrm{I} / \mathrm{R}$ rats significantly upregulated the PPAR- $\gamma$ and BDNF expressions while, suppressed NF- $\kappa \mathrm{B}$ when compared with the untreated cerebral I/R group $(\mathrm{P}<0.05)$. Conversely, the BADGE pretreatment to I/R-TQ treated group 
showed a significant decrease in PPAR- $\gamma$ and BDNF expressions with a significant increase in $\mathrm{NF}-\kappa \mathrm{B}$ expression when compared with the cerebral I/R-TQ treated group.

\section{Discussion}

Cerebrovascular insults contribute significantly to morbidity and mortality statistics worldwide. The majority of stroke patients are ischemic either focal or global ${ }^{[27]}$. In the current study, we performed global cerebral $\mathrm{I} / \mathrm{R}$ injury to ensure diffuse brain injury with the selective and delayed neuronal damage of the hippocampus, being a vulnerable brain area that firstly suffers ischemic damage, that subsequently causes evident behavioral and cognitive deficits ${ }^{[4]}$.

The brain, due to its high oxygen consumption and lipid-rich content, is highly susceptible to ischemic injury that can be recovered via early reperfusion. However, this reperfusion can, itself, turn out to be a start for neuronal damage through superoxide and other reactive oxygen species generation at the onset of blood reintroduction, causing disruption of the overall redox system then oxidative stress injury ${ }^{[28]}$. This goes hands with our findings that revealed elevated MDA (a marker of lipid peroxidation) and depleted SOD and GSH-Px (antioxidant markers) in the hippocampus of rats subjected to global cerebral I/R operation compared to sham. In addition, a significant increase in the hippocampal expression of the proinflammatory transcription factor, NF- $\kappa \mathrm{B}$ and its downstream inflammatory cytokines TNF- $\alpha$ and IL-6 in ischemic rats versus sham was also, documented. An increase in these oxidants and inflammatory molecules play a vigorous role in the progression of post-ischemic brain injury and is sufficient to induce neuronal damage within the hippocampus ${ }^{[29,}$ 30].

The hippocampus is concerned with short-term memory consolidation to long-term and in spatial memory ${ }^{[4]}$ through synaptic plasticity, long term potentiation, neurotransmitters modulation and proteins synthesis ${ }^{[6]}$. At the functional level, NOR test was used in the current work to assess the memory performance of ischemic rats. During this test, the rats were exposed to the same familiar object at 3 different time intervals $2 \mathrm{hs}, 24 \mathrm{hs}$, and 7days after the sample phase, so as to evaluate the status of short-term, long-term, and persistent memory respectively. The ischemic rats were unable to recall information concerning the familiar object and can't discriminate between it and the novel object, as presented by significant decreases in the discrimination index and ratio when compared to the sham group. It thus, confirms the hippocampal neuronal damage that has resulted in memory and cognitive deficits. Our findings were in agreement with previous researches executed by Ashabi et al. ${ }^{[31]}$ and Schmidt et al. ${ }^{[32]}$. They have reported significant memory impairments in cerebral I/R model by using NOR test.

Although of rising understanding of the mechanisms of neuronal injury accompanying cerebral I/R injury, effective therapy has remained obscure. TQ, the active ingredient in the seeds of Nigella sativa plant, is becoming an emerging natural medication with a varied range of medical applications. Additionally, accumulating pieces of evidence pointed out that TQ is efficient to protect neurons from neuropathological and neurotoxic challenges and help their survival ${ }^{[14-16,33,34]}$. Thus, we planned to investigate the potential beneficial role of TQ co- and post-conditioning on memory deficits accompanies cerebral I/R.

Behavioral results of NOR test indicated a significant improvement in the memory performance of TQ-treated ischemic rats during the 2hs, 24hs, and 7 days choice phases. These rats kept in memory the initial information concerning the familiar object and can distinguish it from the novel one. Thus, they spent more time exploring the novel object compared to the familiar one. This was presented by a significant increase in the discrimination index and ratio compared to the untreated one. In supporting of our findings, various studies reported the valuable effect of TQ on memory impairment in various models $[14-16,33]$ but, to the best of our knowledge, this is the first study reporting a protective effect on memory deficits accompanies cerebral I/R.

TQ supplementation improved cerebral I/Rinduced oxidative stress in the hippocampal tissue. Our data revealed up growing levels of SOD and GSH-Px combined with lowering MDA levels in the TQ-treated ischemic rats. In supporting of our findings, TQ has been suggested as a 
neuroprotective agent against global cerebral I/R injury model ${ }^{[33]}$ Parkinson's disease ${ }^{[35]}$, in addition to an epileptic rat model ${ }^{[36]}$, on basis of antioxidant impact. The TQ antioxidant activity could be attributable to its reduced form tertbutylhydroquinone. It acts as a hydrogen donor antioxidant that inhibits lipid peroxidation. Additionally, TQ has a direct scavenging effect of multiple ROS that mimicking SOD activity ${ }^{[37]}$. As a side note, TQ administration to sham rats improved the memory status as well. That was accompanied by a significant increase in the antioxidant enzymes and decrease in MDA levels compared to the untreated one, indicating that TQ is exerting potent antioxidant properties under sham conditions. This was in agreement with Sahak et al. ${ }^{[38]}$. They reported enhanced memory performance in rats administrated Nigella sativa oil through antioxidant effect in addition to acetyl choline preservative effect which is essential for memory encoding.

Regarding the inflammatory response in our experimental model of hippocampal injury-induced by cerebral I/R, TQ administration downregulated hippocampal NF- $\mathrm{B}$ expression and its downstream inflammatory cytokines TNF- $\alpha$ and IL-6 levels, indicating potent TQ anti-inflammatory effect. The proinflammatory transcription factor $\mathrm{NF}-\kappa \mathrm{B}$ is activated in response to various inflammatory and oxidants stimuli. On activation, NF- $\kappa \mathrm{B}$ translocates from the cytoplasm to the nucleus, binds DNA, and causes gene transcription of chemokines, cytokines and adhesion molecules [39]. TQ was found to decrease the phosphorylated-P65 subunit of NF- $\kappa$ B. In addition, it interferes with $\mathrm{NF}-\kappa \mathrm{B}$ binding to DNA ${ }^{[40]}$. These results are consistent with that of Bargia et al. ${ }^{[16]}$ who revealed that administration of TQ was accompanied with a reduction in hippocampal IL-6 and TNF- $\alpha$ content and improving learning and memory deficits induced by lipopolysaccharide in rats [16]. Also, other researchers have also suggested that TQ exerted anti-inflammatory properties by suppressing NF- $\kappa \mathrm{B}$ and inhibition of cytokine production ${ }^{[41]}$.

TQ administration in ischemic rats also resulted in a significant rise in the hippocampal BDNF expression levels compared to the untreated group. BDNF induces memory persistence and converts a non-lasting long-term memory trace into a persistent one, denoting a protective impact on synaptic transmission and cognitive functions ${ }^{[42]}$. In addition, BDNF prevents neuronal death, mend pathological changes and expedite the regeneration and differentiation process of injured neurons. Constantly, the expression level of BDNF was positively correlated with the capacity of neurons to tolerate ischemic injury following brain ischemia ${ }^{[43]}$. Our findings were in agreement with an earlier one that investigated the effect of BDNF administration on hippocampal cognitive functions after global cerebral $I / R$ in rats using a passive avoidance test. The BDNF-administrated ischemic rats showed improved working memory 15 days after ischemia ${ }^{[44]}$. Furthermore, upregulated BDNF within the hippocampus following voluntary exercise, induced improvements in cognitive performance after traumatic brain injury in rats ${ }^{[45]}$.

Noteworthy, PPAR- $\gamma$ is becoming a promising therapeutic target for cognitive impairment in animal models of stroke, traumatic brain injury, and degenerative brain diseases [46]. Consistency, neuron-specific PPAR- $\gamma$ knockout mice experienced significant brain damage and oxidative stress in response to ischemic insult ${ }^{[47]}$. In the acute injury phase, PPAR- $\gamma$ directly restricts tissue damage by motivating the antioxidant mechanisms and reducing free radicals generation to neutralize oxidative stress and hindering the NF- $\kappa \mathrm{B}$ pathway to mitigate inflammation. During the chronic phase of acute brain injuries, PPAR- $\gamma$ activation in injured cells ends in the repair of gray and white matter, resolution of inflammation, and long-term functional recovery ${ }^{[7]}$. Furthermore, the PPAR$\gamma / \mathrm{BDNF}$ pathway is involved in improving synaptic function in hippocampal neurons by increasing BDNF expression ${ }^{[48]}$. Similarly, PPAR- $\gamma$ upregulation had increased BDNF level in Amyloid- $\beta$ injected rats which were correlated with recovered synaptic plasticity ${ }^{[49]}$.

Additionally, a recently published study has documented cross-talk between TQ and PPAR-r ${ }^{[13]}$. In view of these considerations, we supposed the neuroprotective and memory preservative effects of TQ might, at least in part, involve the PPAR- $\gamma$ pathway as a potential molecular mechanism. First, we evaluated hippocampal PPAR- $\gamma$ levels. Our data revealed significant PPAR- $\gamma$ upregulation in the TQ-treated ischemic rats compared to the untreated group. Next, BADGE a pure PPAR- $\gamma$ antagonist 
was used to investigate the possible involvement of PPAR- $\gamma$ pathway ${ }^{[18]}$. We found that the prior treatment with BADGE attenuated the TQ protective effect on memory, oxidative stress, inflammatory response, and BDNF. This indicates that PPAR- $\gamma$ functions are required for TQmediated neuroprotective effect in ischemic rats. In supporting of our data, an earlier study has proven that TQ was able to increase PPAR- $\gamma$ activity that was prohibited in the presence of PPAR- $\gamma$ specific inhibitor ${ }^{[50]}$. Similar findings were reported in various tissues in spinal cord injury ${ }^{[13]}$ and in the liver as well ${ }^{[51]}$.

In conclusion, the data of the present study revealed, for the first time, TQ administration improved the memory performance in rats with global cerebral $\mathrm{I} / \mathrm{R}$ injury using NOR test. The hippocampal neuroprotective effects of TQ include improving oxidative stress, inflammatory responses, and promoting neurogenesis. Such effects were attenuated with the prior BADGE treatment, indicating that PPAR- $\gamma$ contributes partly, toward TQ-mediated protection. To the best of our knowledge, this study provides a shred of early evidence for the possible involvement the PPAR-Y in TQ-mediated defense that requires further molecular and behavioral investigations.

\section{Disclaimer statements}

\section{Conflict of interest: None \\ Funding:None \\ Ethical approval}

All applicable international, national, and/or institutional guidelines for the care and the use of animals were followed and approved by the Ethical Committee of Animal Experiments, Faculty of Medicine, Benha University, Egypt.

\section{References}

1 Tian, S., Zhang, Y., Yang, X., Yu, K., Shen, X., Zhang, L., et al.Early exercise training improves ischemic outcome in rats by cerebral hemodynamics. Brain Research.2013 1533: 114-121.

DOI:doi.org/10.1016/j.brainres.2013.07.049

2 Cechetti, F.,Worm, P.V., Elsner, V. R.,Bertoldi, K., Sanches, E., Ben, J., et al. Forced treadmill exercise prevents oxidative stress and memory deficits following chronic cerebral hypoperfusion in the rat. Neurobiology of Learning and Memory.2012 97: 90-96. DOI:doi.org/10.1016/j.nlm.2011.09.008

3 Ashabi, G.,Khodagholi, F.,Khalaj, L., Goudarzvand, M., and Nasiri, M. Activation of AMP activated protein kinase by metformin protects against global cerebral ischemia in male rats: interference of AMPK/PGC-1alpha pathway. Metab. Brain. Dis.2014 29(1): 47-58. DOI:10.1007/s11011-013-9475-2

4 Anderson, P., Morris, R., Amaral, Bliss, T.and O'Keefe, J.. "The hippocampal formation". The hippocampus book (first ed.). New York: Oxford University Press.2007 p.3. ISBN 9780-19-510027-3.

5 Xu, F., Li, J., Ni, W., Shen, Y. W., and Zhang, X.P. Peroxisome proliferator-activated receptor- $\gamma$ agonist 15d-prostaglandin J2 mediates neuronal autophagy after cerebral ischemia-reperfusion injury. PloS one,2013 $8(1)$, e55080.DOI:

\subsection{1/journal.pone. 0055080}

6 Xie, H., Leung, K. L., Chen, L., Chan, Y. S., Ng, P.C.,Fok,T.F.,et al. Brain-derived neurotrophic factor rescues and prevents chronic intermittent hypoxia-induced impairment of hippocampal long-term synaptic plasticity. Neurobiol. Dis. 2010 40(1): 155-162. DOI: 10.1016/j.nbd.2010.05.020

7 Cai, W., Yang, T., Liu, H., Han, L., Zhang, K., $\mathrm{Hu}$, X., Zhang, X., Yin, K.J., Gao, Y., Bennett, M.V. and Leak, R.K. Peroxisome proliferatoractivated receptor $\gamma$ (PPAR $\gamma)$ : A master gatekeeper in CNS injury and repair. Progress in neurobiology, 2018 163, pp.27-58. DOI:doi.org/10.1016/j.pneurobio.2017.10.002

8 Aleshin, S., Strokin, M., Sergeeva, M., and Reiser, G. Peroxisome proliferator-activated receptor (PPAR) $\beta / \delta$, a possible nexus of PPAR $\alpha$ - and PPAR $\gamma$-dependent molecular pathways in neurodegenerative diseases: review and novel hypotheses. Neurochem. Int.2013 63: 322-330. DOI: 10.1016/j.neuint.2013.06.012

9 Huang, T., Gao, D., Hei, Y., Zhang, X., Chen, X., and Fei, Z. D-allose protects the blood brain barrier through PPAR $\gamma$-mediated anti- 
inflammatory pathway in the mice model of ischemia reperfusion injury. Brain Res.2016 1642: 478-486. DOI: 10.1016/j.brainres.2016.04.038

10 Shabana A., El-Menyar A., Asim M., Al-Azzeh H., Al Thani H.Cardiovascular benefits of black cumin (Nigella sativa) Cardiovascular, Toxicology.2013 13(1):9-21. DOI: $\underline{10.1007 / \mathrm{s} 12012-012-9181-\mathrm{Z}}$

11 Al-Majed, AA., Al-Omar, FA. and Nagi, MN. Neuroprotective effects of thymoquinone against transient forebrain ischemia in the rat hippocampus. Eur J Pharmacol.2006 543(13):40-7. DOI:10.1016/j.ejphar.2006.05.046

12 Hosseinzadeh, $\mathrm{H}$. and Parvardeh , S. Anticonvulsant effects of thymoquinone, the major constituent of Nigella sativa seeds, in mice. Phytomedicine. 2004 11(1):56-64. DOI: $10.1078 / 0944-7113-00376$

13 Chen,Y.,Wang, B.and Zhao, H.Thymoquinone reduces spinal cord injury by inhibiting inflammatory response, oxidative stress and apoptosis via PPAR- $\gamma$ and PI3K/Akt pathways Experimental and therapeutic medicine.2018 15: 4987-4994. DOI:doi.org/10.3892/etm.2018.6072

14 Salehi,P.,Nasri,S.,Roghani,M.,Poordahandeh,U. Baluchnejadmojarad,T. The effect of thymoquinone on short-term spatial memory, passive avoidance learning and memory of diabetic rats and the involvement of hippocampal oxidative stress.pajoohande journal.2012 17(5): 219-227. http://pajoohande.sbmu.ac.ir/article-1-1392en.html

15 Baghcheghi, Y., Hosseini,M., Beheshti,F., Salmani,H.Anaeigoudari,A.Thymoquinone reverses learning and memory impairments and brain tissue oxidative damage in hypothyroid juvenile rats. Arq Neuropsiquiatr. 2018 76(1):32-

40.DOI:dx.doi.org/10.1590/0004$\underline{282 \times 20170182}$

16 Bargia,R., Asgharzadehb,F., Beheshtic, F., Hosseinia,M., Sadeghniad HR. and Majid Khazaeib,M. The effects of thymoquinone on hippocampal cytokine level, brain oxidative stress status and memory deficits induced by lipopolysaccharide in rats. Cytokine. 2017 96 :173-184. DOI: $10.1016 /$ j.cyto.2017.04.015

17 Poorgholam, P., Yaghmaei, P. and Hajebrahimi, Z.Thymoquinone recovers learning function in a rat model of Alzheimer's disease.Avicenna $\mathbf{J}$ Phytomed, $2018 \quad 8 \quad$ (3): $188-197$. PMID: 29881705

18 Wright, H. M., Clish, C. B., Mikami, T., Hauser, S., Yanagi, K., Hiramatsu, R., ... \& Spiegelman, B. M.A synthetic antagonist for the peroxisome proliferator-activated receptor $\gamma$ inhibits adipocyte differentiation. Journal of Biological Chemistry,2000 275(3), 1873-1877. DOI: $10.1074 / \mathrm{jbc} .275 .3 .1873$

19 Singh, B., Sharma, B., Jaggi, A. S., \& Singh, N. Attenuating effect of lisinopril and telmisartan in intracerebroventricular streptozotocin induced experimental dementia of Alzheimer's disease type: possible involvement of PPAR- $\gamma$ agonistic property. Journal of the ReninAngiotensin-Aldosterone System,2013 14(2), 124-136.

DOI:doi.org/10.1177\%2F1470320312459977

20 Can, B., Oz, S., Sahinturk, V., Musmul, A., \& Alatas, İ. O. Effects of Conivaptan versus Mannitol on Post-Ischemic Brain Injury and Edema. The Eurasian journal of medicine. $2019 \quad 51(1), \quad 42 . \quad$ DOI $\underline{10.5152 / \text { eurasianjmed.2019.18368 }}$

21 Pérez-García,G., Omar Guzmán-Quevedo,O., Silva Aragão, RD., and Francisco BolañosJiménez,F.Early malnutrition results in longlasting impairments in patternseparation for overlapping novel object and novel location memories and reduced hippocampal neurogenesis. Scientific Reports.2016 6:21275 DOI: $10.1038 /$ srep21275

22 Mostafaa, RM.,Mostafaa Y M.Abdelkader Ennaceurc,A.Effects of exposure to extremely low-frequency magnetic field of $2 \mathrm{G}$ intensity on memory and corticosterone level in rats. Physiology \& Behavior.2002 76 : 589- 595. DOI:doi.org/10.1016/S0031-9384(02)00730-8

23 Sun Y, Oberley LW, Li Y,A simple method for clinical assay of superoxide dismutase. Clin Chem. 1998 34:497-500. PMID:3349599

24 Paglia, DE. and Valentine, WN.Studies on the quantitative and qualitative characterization of 
erythrocyte glutathione peroxidase. $\boldsymbol{J}$ Lab Clin Med.1967 70:158-169.

25 Ohkawa, H., Ohish, N. and Yagi, K. Assay for lipid peroxides in animal tissues by thiobarbituric acid. Anal. Biochem.1979 95: 351-358. DOI:doi.org/10.1016/00032697(79)90738-3

26 Carniglia, L.,Durand, D., Caruso, C.Lasaga, M.Effect of NDP- $\alpha$-MSH on PPAR- $\gamma$ and $-\beta$ Expression and Anti-Inflammatory Cytokine Release in Rat Astrocytes and Microglia. PLoS ONE.2013 8(2): e57313. DOI: 10.1371/journal.pone.0057313

27 Wan, L.;Cheng, Y.; Luo, Z.; Guo, H.; Zhao, W.; Gu, Q.; Yang, X.; Xu, J.; Bei, W.; Guo, J. Neuroprotection, learning and memory improvement of a standardized extract from Renshen Shouwu against neuronal injury and vascular dementia in rats with brain ischemia. J. Ethnopharmacol. 2015, 165, 118-126. DOI: 10.1016/j.jep.2015.02.027

28 Dirnagl, U.; Lindauer, U.; Them, A.; Schreiber, S.; Pfister, H.W.; Koedel, U.; Reszka, R.; Freyer, D.; Villringer, A.Global cerebral ischemia in the rat: Online monitoring of oxygen free radical production using chemiluminescence in vivo. J. Cereb. Blood Flow Metab. 1995, 15, 929-940. DOI:doi.org/10.1038\%2Fjcbfm.1995.118

29 Salim,S.Oxidative Stress and the Central Nervous System. J Pharmacol Exp Ther.2017 360(1): 201-205. DOI: doi.org/10.1124/jpet.116.237503

30 Zhou,W.W., Lu,S., Su, Y.-J. , Xue, D. , Yu, X.L.,Wang, S.-W.et al. Decreasing oxidative stress and neuroinflammation with a multifunctional peptide rescues memory deficits in mice with Alzheimer disease. Free Radical Biol. Med. 201474 :50-63. DOI:doi.org/10.1016/j.freeradbiomed.2014.06. $\underline{013}$

31 Ashabi,G., Sarkaki,A., Khodagholi,F., Shahamati,S.Z., Goudarzvand, M. ,Farbood, Y. et al.Subchronic metformin pretreatment enhances novel object recognition memory task in forebrain ischemia: behavioural, molecular, and electrophysiological studies.

Canadian Journal of Physiology and Pharmacology. 2017 95(4): $388-395$.
DOI:doi.org/10.1016/j.freeradbiomed.2014.06. $\underline{013}$

32 Schimidt ,H.L., Vieira,A., Altermann,C., Martins,A., Sosa,P. ,Santos,F.W.et al.Memory deficits and oxidative stress in cerebral ischemia- reperfusion: Neuroprotective role of physical exercise and green tea supplementation. Neurobiology of Learning and Memory. $2014 \quad 114$ : 242-250. DOI:doi.org/10.1016/j.nlm.2014.07.005

33 Hosseinzadeh, H., Parvardeh, S., Asl, MN., Sadeghnia, HR.and Ziaee, T.Effect of thymoquinone and Nigella sativa seeds oil on lipid peroxidation level during global cerebral ischemia-reperfusion injury in rat hippocampus. Phytomedicine. 2007 14(9):621-7. DOI:doi.org/10.1016/j.phymed.2006.12.005

34 Megantara, S. , Utami, D., Puspitasari ,L., and Mustarichie,R.Insilico Study of Thymoquinone as Peroxisome Proliferator Activated Receptor Gamma Agonist in the Treatment of Type 2 Diabetes Mellitus. Pharm. Sci. \& Res.2018 9(9): 1478-1482

35 Ebrahimi, SS., Oryan, S., Izadpanah, E. and Hassanzadeh, K.Thymoquinone exerts neuroprotective effect in animal model of Parkinson's disease. Toxicol Lett.2017 276:108-

14. DOI:doi.org/10.1016/j.toxlet.2017.05.018

36 Shao, YY., Li, B., Huang, YM., Luo, Q., Xie, YM. and Chen, YH. Thymoquinone attenuates brain injury via an antioxidative pathway in a status epilepticus rat model. Transl Neurosci. 2017 8(1):9-14. DOI: $\underline{10.1515 / \text { tnsci-2017-0003 }}$

37 Badary OA, Taha RA, Gamal el-Din AM, Abdel-Wahab MH. Thymoquinone is a potent superoxide anion scavenger. Drug Chem Toxicol,2003 26(2):87-98. DOI:10.1081/DCT120020404

38 Sahak, M. K. A., Mohamed, A. M., Hashim, N. H., Adli, H., \& Sharifah, D.Nigella sativa oil enhances the spatial working memory performance of rats on a radial arm maze. Evidence-Based Complementary and Alternative Medicine, 2013. DOI:dx.doi.org/10.1155/2013/180598

39 Zhang, Y., Hu, L., Cui, Y., Qi, Z., Huang, X., Cai, L.,Xiang, J.Roles of PPAR $\gamma / \mathrm{NF}-\kappa \mathrm{B}$ signaling pathway in the pathogenesis of 
intrahepatic cholestasis of pregnancy. PLoS One,2014 9(1), e87343. DOI:doi.org/10.1371/journal.pone. 0087343

40 Zhang L.,Bai Y.,Yang Y.Thymoquinone chemosensitizes colon cancer cells through inhibition of NF- $\mathrm{kB}$. Oncol let.2016 12(4):2840-2845.

DOI:doi.org/10.3892/ol.2016.4971

41 Beheshti, F., Khazaei, M.and Hosseini, M.Neuropharmacological effects of Nigella sativa, Avicenna J. Phytomed.2016 6 (1) 104116.

42 Bekinschtein $\mathrm{P}$, Cammarota $\mathrm{M}$, Katche $\mathrm{C}$, et al. BDNF is essential to promote persistence of long-term memory storage. Proc Natl Acad Sci USA. 2008 105: 2711-2716. DOI:doi.org/10.1073/pnas.0711863105

$43 \mathrm{Xu} \mathrm{H}$ and Heilshorn SC, Microfluidic investigation of BDNF-enhanced neural stem cell chemotaxis in CXCL12 gradients. Small. 2013 9:585-595. DOI: 10.1002/smll.201202208

44 Kiprianova I, Sandkuhler J, Schwab S, Hoyer S and Spranger M.Brain-derived neurotrophic factor improves long-term potentiation and cognitive functions after transient forebrain ischemia in the rat. Exp Neurol.1999 159: 511-519.DOI:doi.org/10.1006/exnr.1999.7109

45 Griesbach GS, Hovda DA and Gomez-Pinilla F.Exercise-induced improvement in cognitive performance after traumatic brain injury in rats is dependent on BDNF activation. Brain Res. 2009 1288: $105-115$. DOI: $\underline{10.1016 / \text { j.brainres.2009.06.045 }}$
46 Liu, B.,He, Y., Lu, R.,Zhou, J., Bai, L., Zhang, P., et al.Zhen-wu-tang protects against podocyte injury in rats with iga nephropathy via PPARg/nf- $\mathrm{kb}$ pathway. Biomed. Pharmacother. 2018 101, 635-647. DOI: 10.1016/j.biopha.2018.02.127

47 Zhao, X., Strong, R., Zhang, J., Sun, G., Tsien, J.Z., Cui, Z., Grotta, J.C. and Aronowski, J., Neuronal PPAR $\gamma$ deficiency increases susceptibility to brain damage after cerebral ischemia. Journal of Neuroscience,2009 29(19), pp.6186-6195. DOI: doi.org/10.1523/JNEUROSCI.5857-08.2009

48 Kariharan,T.,Nanayakkara, G.,Parameshwaran, K., Bagasrawala, I., Ahuja, M., Abdel-Rahman, E.,Amin, R. H.Central activation of PPARgamma ameliorates diabetes induced cognitive dysfunction and improves BDNF expression. Neurobiology of aging,2015 36(3), 1451-1461. DOI:doi.org/10.1016/j.neurobiolaging.2014.09. $\underline{028}$

49 Prakash, A., Kumar, A.Role of nuclear receptor on regulation of BDNF and neuroinflammation in hippocampus of $\beta$-amyloid animal model of Alzheimer's disease. Neurotoxicity research,2014 25(4), 335-347. DOI: 10.1007/s12640-013-9437-9

50 Woo, C. C., Loo, S. Y., Gee, V., Yap, C. W., Sethi, G., Kumar, A. P.,Tan, K. H. B. Anticancer activity of thymoquinone in breast cancer cells: possible involvement of PPAR- $\gamma$ pathway. Biochemical pharmacology,2011 $82(5)$, 464-475.DOI: 10.1016/j.bcp.2011.05.030

51 Prabhakar, P., Reeta, K. H., Maulik, S. K., Dinda, A. K., \& Gupta, Y. K.Effect of thymoquinone on high fructose diet-induced metabolic syndrome in rats. Journal of Molecular and Cellular Cardiology,2017 112, 152. DOI:doi.org/10.1007/s00394-014-0788-7 